\title{
Hormonal regulation of regucalcin mRNA expression in osteoblastic MC3T3-E1 cells
}

\author{
MASAYOSHI YAMAGUCHI ${ }^{1,2}$, YASUKO OTOMO ${ }^{1}$, \\ SATOSHI UCHIYAMA $^{1}$ and TAEKO NAKAGAWA ${ }^{1}$ \\ ${ }^{1}$ Laboratory of Endocrinology and Molecular Metabolism, Graduate School of \\ Nutritional Sciences, University of Shizuoka, 52-1 Yada, Shizuoka 422-8526, Japan
}

Received December 4, 2007; Accepted January 28, 2008

\begin{abstract}
The effect of various hormones on regucalcin mRNA expression in osteoblastic MC3T3-E1 cells in vitro was investigated. Cells with subconfluency were cultured for 24 or $48 \mathrm{~h}$ in a medium containing either vehicle or various hormones without fetal bovine serum. Regucalcin mRNA expression was significantly increased after culture with parathyroid hormone (synthetic human PTH; $10^{-7} \mathrm{M}$ ), insulinlike growth factor-I (IGF-I; $\left.10^{-8} \mathrm{M}\right)$, or 173 -estradiol $\left(10^{-10}\right.$ or $10^{-9} \mathrm{M}$ ) for $48 \mathrm{~h}$. Culture with 1,25-dihydroxyvitamin $\mathrm{D}_{3}$ $\left(10^{-7} \mathrm{M}\right)$ for $48 \mathrm{~h}$ caused a significant decrease in regucalcin mRNA expression. Regucalcin mRNA expression was significantly decreased after culture with tumor necrosis factor- $\alpha$ ( 1 or $10 \mathrm{ng} / \mathrm{ml}$ of medium) for 24 or $48 \mathrm{~h}$. The effect of PTH or IGF-I in increasing regucalcin mRNA expression was not seen in the presence of staurosporine $\left(10^{-8} \mathrm{M}\right)$, an inhibitor of protein kinase C, or PD98059 $\left(10^{-7} \mathrm{M}\right)$, an inhibitor of mitosis-activated protein kinase (MAP kinase), respectively, suggesting that regucalcin mRNA expression is enhanced through intracellular signaling factors. This study demonstrated that regucalcin mRNA expression in osteoblastic MC3T3-E1 cells is regulated by various hormones.
\end{abstract}

\section{Introduction}

Regucalcin was discovered in 1978 as a $\mathrm{Ca}^{2+}$-binding protein that does not contain the EF-hand motif of the $\mathrm{Ca}^{2+}$-binding domain (1-5). The name regucalcin was proposed for this $\mathrm{Ca}^{2+}$-binding protein, which regulates the $\mathrm{Ca}^{2+}$ effect on

Correspondence to: Dr Masayoshi Yamaguchi, ${ }^{2}$ Present address: Division of Endocrinology and Metabolism and Lipids, Department of Medicine, Emory University School of Medicine, 1639 Pierce Drive, 1305 WMRB, Atlanta, GA 30322-0001, USA E-mail: yamamasa1155@yahoo.co.jp

Key words: regucalcin, parathyroid hormone, insulin-like growth factor-I, 17ß-estradiol, 1,25-dihydroxyvitamin $\mathrm{D}_{3}$, gene expression, osteoblast various enzyme activities $(4,6)$. In recent years, it has been demonstrated that regucalcin plays a multifunctional role as a regulatory protein in intracellular signaling processes in many cell types (reviewed in 6-9).

The regucalcin gene is highly conserved in vertebrate species $(5,10)$. The rat and human regucalcin genes are localized on chromosome X $(11,12)$. Regucalcin mRNA and its protein are strongly present in liver and kidney cortex $(13,14)$, and only slightly present in other tissues. AP1, NF1-A1, and RGPR-p1 17 have been found to be transcriptional factors for the enhancement of regucalcin gene promoter activity (15-18): RGPR-p117 was found to be a novel protein. The expression of regucalcin mRNA is mediated through a signaling mechanism $(16,19,20)$.

Regucalcin has been shown to play a role in the maintenance of intracellular $\mathrm{Ca}^{2+}$ homeostasis, the inhibitory regulation of various $\mathrm{Ca}^{2+}$-dependent protein kinases, tyrosine kinases and protein phosphatases, and nitric oxide synthase (6-9). Regucalcin has suppressive effects on nuclear DNA and RNA syntheses in proliferative cells $(9,21,22)$. Regucalcin is translocated into the nuclei (23), and it regulates the expression of various genes (24).

Overexpression of regucalcin modulated and suppressed cell proliferation in cloned rat hepatoma H4-II-E cells (25) and in cloned normal rat kidney proximal tubular epithelial NRK52E cells (26), and it has been shown to have suppressive effects on cell death and apoptosis induced with stimulation of various factors in H4-II-E cells (27) and NRK52E cells (28). It has been proposed that regucalcin plays a physiologic role in the maintenance of homeostasis of cellular response for cell stimulation (reviewed in 12).

Regucalcin transgenic (TG) rats were generated to determine the regulatory role of endogenous regucalcin in vivo (29). Bone loss and hyperlipedemia have been demonstrated in regucalcin TG rats, indicating that regucalcin plays a role in the regulation of bone and lipid metabolisms $(30,31)$.

Regucalcin has been shown to have stimulatory effects on osteoclastogenesis and bone resorption (32) and suppressive effects on osteoblastic differentiation and mineralization in vitro (33). Regucalcin may regulate bone mass.

This study was undertaken to determine whether the expression of regucalcin mRNA in osteoblastic cells is hormonally regulated in vitro. We found that regucalcin mRNA expression was enhanced after culture with parathyroid 
hormone, insulin-like growth factor-I, or 17ß-estradiol, and that it was suppressed with 1,25-dihydroxyvitamin $\mathrm{D}_{3}$ or tumor necrosis factor- $\alpha$.

\section{Materials and methods}

Chemicals. $\alpha$-minimal essential medium ( $\alpha$-MEM) and penicillin-streptomycin $(5,000 \mathrm{U} / \mathrm{ml}$ penicillin; $5,000 \mu \mathrm{g} / \mathrm{ml}$ streptomycin) were obtained from Gibco Laboratories. Fetal bovine serum (FBS) was obtained from Bioproducts Inc. Parathyroid hormone [PTH; synthetic human PTH (1-34)], insulin-like growth factor-I (IGF-I), 17ß-estradiol, 1,25dihydroxyvitamin $\mathrm{D}_{3}\left[1,25(\mathrm{OH})_{2} \mathrm{D}_{3}\right]$, tumor necrosis factor- $\alpha$ (TNF- $\alpha$ ), staurosporine, and PD98059 were purchased from Sigma Chemicals (St. Louis, MO). Other chemicals were of reagent grade and were obtained from Wako Pure Chemical Industries (Osaka, Japan). All water used was glass distilled.

Cell culture. Osteoblastic MC3T3-E1 cells were cultured at $37^{\circ} \mathrm{C}$ in a $\mathrm{CO}_{2}$ incubator in plastic dishes containing $\alpha$-MEM supplemented with $10 \%$ FBS. They were subcultured every 3 days using $0.2 \%$ trypsin plus $0.02 \%$ EDTA in $\mathrm{Ca}^{2+} / \mathrm{Mg}^{2+}$-free phosphate-buffered saline (PBS). For experiments, about $1.0 \times 10^{5}$ cells per dish were cultured for $72 \mathrm{~h}$ to obtain subconfluent monolayers in a $35-\mathrm{mm}$ plastic dish containing $2 \mathrm{ml} \alpha$-MEM with $10 \%$ FBS. After the cells were rinsed with PBS, the medium was exchanged for medium without FBS containing either vehicle or various hormones, and the cells were cultured further for 24 or $48 \mathrm{~h}$. Cell viability was estimated using staining with trypan blue.

Cell counts. After trypsinization of each of the culture dishes using a $0.2 \%$ trypsin plus $0.02 \%$ EDTA in $\mathrm{Ca}^{2+} / \mathrm{Mg}^{2+}$-free PBS for $2 \mathrm{~min}$ at $37^{\circ} \mathrm{C}$, the cells were collected and centrifuged in a PBS solution at $100 \mathrm{x} \mathrm{g}$ for $5 \mathrm{~min}$. The cells were re-suspended on PBS solution and stained with eosin. Cell numbers were counted under a microscope using a hemacytometer plate. For each dish, we took the average of two counts.

Preparation of RNA. Total RNAs were prepared as described previously (34). Osteoblastic MC3T3-E1 cells were homogenized in a buffer solution containing $4 \mathrm{M}$ guanidinium thiocyanate, $24 \mathrm{mM}$ sodium citrate ( $\mathrm{pH} 7.0), 0.5 \%$ sarcosyl, and isoamyl alcohol, and the phases were separated by centrifugation at $10,000 \times \mathrm{g}$ for $20 \mathrm{~min}$ at $4^{\circ} \mathrm{C}$. RNA located in the aqueous phase was precipitated with isoprepanol at $-20^{\circ} \mathrm{C}$. RNA precipitates were pelleted by centrifugation, and the pellets were redissolved in diethylpyrocarbonate-treated water.

Reverse transcriptional-polymerase chain reaction ( $R T-P C R)$ analysis. RT-PCR was performed with a Titan ${ }^{\text {TM }}$ One Tube RT-PCR kit (Roche Molecular Biochemicals, Indianapolis, IN) as recommended by the supplier to determine the gene expression of regucalcin or glyceroaldehyde-3-phosphate dehydrogenase (G3PDH). The primers generated were based on the published rat sequences.

Primers for regucalcin cDNA were 5'-AGATGAACAAA TCCCAGAT-3' (sense strand, positions 618-636 of cDNA

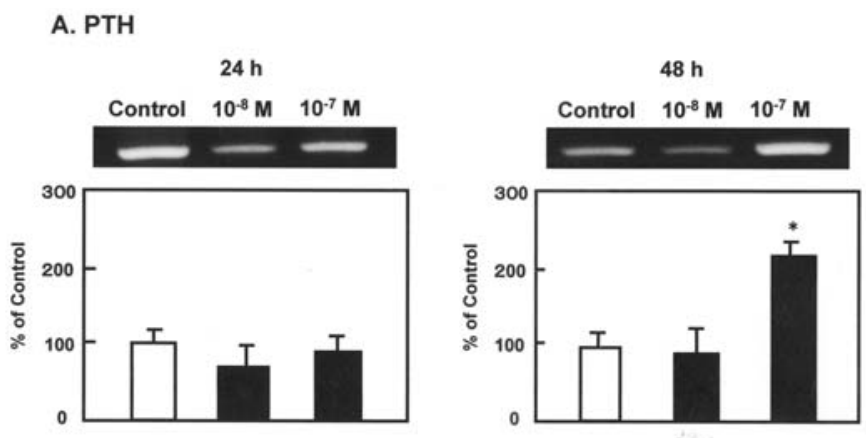

B. IGF-I

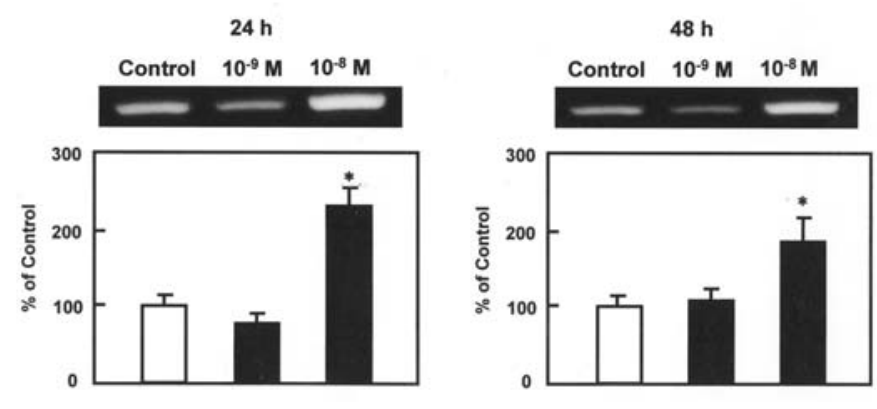

Figure 1. Effect of PTH or IGF-I on regucalcin mRNA expression in osteoblastic MC3T3-E1 cells. Osteoblastic cells were cultured for $72 \mathrm{~h}$ in a medium containing $10 \%$ FBS. Cells with subconfluency were changed to a medium without FBS in the presence or absence of PTH $\left(10^{-8}\right.$ or $\left.10^{-7} \mathrm{M}\right)$ or IGF-I $\left(10^{-9}\right.$ or $\left.10^{-8} \mathrm{M}\right)$. After the medium change, cells were cultured for 24 or $48 \mathrm{~h}$. Total RNAs $(2 \mu \mathrm{g})$ extracted from the cells were analyzed using RT-PCR with specific primers. The figure shows one of four experiments with separate samples. The densitometric data for each mRNA level in the cells cultured for 24 or $48 \mathrm{~h}$ in the presence of PTH (A) or IGF-I (B) were indicated as a percentage of control (mean \pm SEM for four experiments). ${ }^{*} \mathrm{P}<0.01$ compared with the control value.

sequence) and 5'-TCACCCTGCATAGGAATAT-3' (antisense strand, positions 906-924) (10). The pair of oligonucleotide primers was designed to amplify a 307-bp sequence from the mRNA of mouse regucalcin. Primers for G3PDH cDNA were 5'-TGAAGGTCGGTGTGAACGGATTTGGC-3' (sense strand) and 5'-CATGTAGGCCATGAGGTCCACCAC-3' (antisense strand) from the G3PDH Amplimer Set (Clontech, Palo Alto, CA).

RT-PCR was performed using a reaction mixture (20 $\mu \mathrm{l})$ containing 2 or $4 \mu \mathrm{g}$ of total RNAs, supplied RT-PCR buffer, Titan $^{\text {TM }}$ enzyme mix (AMV and Expand ${ }^{\mathrm{TM}}$ High Fidelity), $0.2 \mathrm{mM}$ dNTP, $5 \mathrm{mM}$ dithiothreitol, $5 \mathrm{U}$ RNase inhibitor, and $0.3 \mu \mathrm{M}$ primers. Samples were incubated at $50^{\circ} \mathrm{C}$ for $30 \mathrm{~min}$, and then amplified for 30 cycles under the following conditions: denaturation for $30 \mathrm{sec}$ at $94^{\circ} \mathrm{C}$, annealing for $30 \mathrm{sec}$ at $56^{\circ} \mathrm{C}$, and extension for $60 \mathrm{sec}$ at $68^{\circ} \mathrm{C}$. The amplified products were separated by electrophoresis on a $1.5 \%$ agarose gel and visualized by ethidium bromide staining. Image density was quantified with a FluoroImager SI (Amersham Pharmacia Biotech).

Statistical analysis. Data are expressed as the mean \pm SEM. Statistical differences were analyzed using the Student's t-test. P-values $<0.05$ were considered to indicate statistically 


\section{A. $17 \beta$-Estradiol}
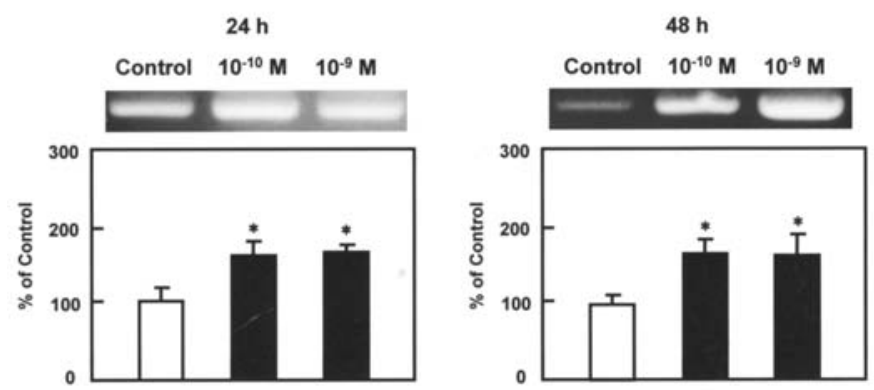

B. $1,25 \mathrm{H}(\mathrm{OH})_{2} \mathrm{D}_{3}$
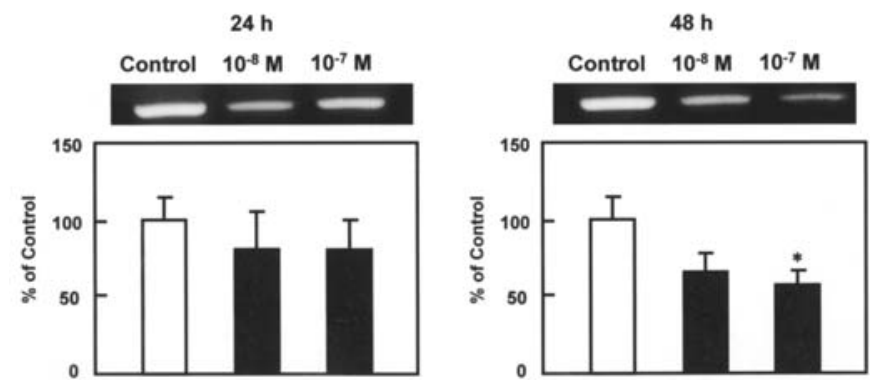

Figure 2. Effect of $17 \mathrm{~B}$-estradiol or $1,25(\mathrm{OH})_{2} \mathrm{D}_{3}$ on regucalcin mRNA expression in osteoblastic MC3T3-E1 cells. Osteoblastic cells were cultured for $72 \mathrm{~h}$ in a medium containing 10\% FBS. Cells with subconfluency were changed to a medium without FBS in the presence or absence of 17B-estradiol $\left(10^{-10}\right.$ or $\left.10^{-9} \mathrm{M}\right)$ or $1,25(\mathrm{OH})_{2} \mathrm{D}_{3}\left(10^{-8}\right.$ or $\left.10^{-7} \mathrm{M}\right)$. After the medium change, the cells were cultured for 24 or $48 \mathrm{~h}$. Total RNAs $(2 \mu \mathrm{g})$ extracted from the cells were analyzed using RT-PCR with specific primers. The figure shows one of four experiments with separate samples. The densitometric data for each mRNA level in the cells cultured for 24 or $48 \mathrm{~h}$ in the presence of $17 \mathrm{~B}$-estradiol (A) or $1,25(\mathrm{OH})_{2} \mathrm{D}_{3}(\mathrm{~B})$ were indicated as a percentage of control (mean \pm SEM for four experiments). ${ }^{*} \mathrm{P}<0.01$ compared with the control value.
$24 \mathrm{~h}$

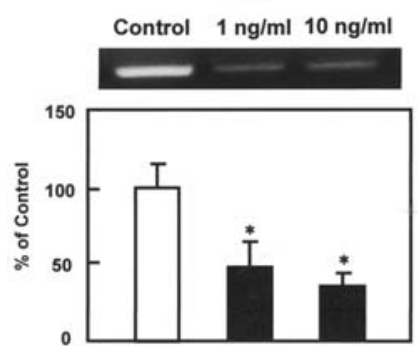

$48 \mathrm{~h}$

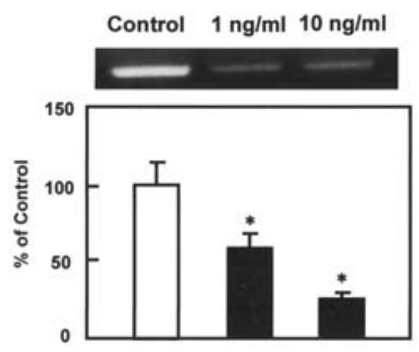

Figure 3. Effect of TNF- $\alpha$ on regucalcin mRNA expression in osteoblastic MC3T3-E1 cells. Osteoblastic cells were cultured for $72 \mathrm{~h}$ in a medium containing $10 \%$ FBS. Cells with subconfluency were changed to a medium without FBS in the presence or absence of TNF- $\alpha$ ( 1 or $10 \mathrm{ng} / \mathrm{ml}$ of medium. After the medium change, the cells were cultured for 24 or $48 \mathrm{~h}$. Total RNAs $(2 \mu \mathrm{g})$ extracted from the cells were analyzed using RT-PCR with specific primers. The figure shows one of four experiments with separate samples. The densitometric data for each mRNA level in the cells cultured for 24 or $48 \mathrm{~h}$ in the presence of $\mathrm{TNF}-\alpha$ were indicated as a percentage of control (mean $\pm \mathrm{SEM}$ for four experiments). ${ }^{*} \mathrm{P}<0.01$ compared with the control value.

significant differences. The ANOVA multiple comparison test was also used to compare the treatment groups.

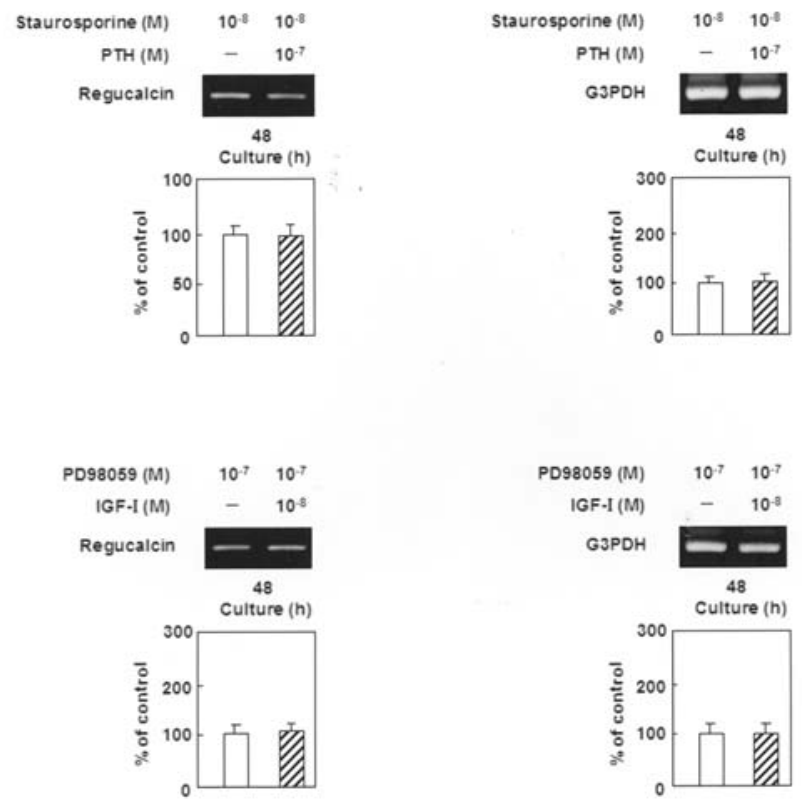

Figure 4. Effect of staurosporine or PD98059 on the PTH- or IGF-Iincreased regucalcin mRNA expression in osteoblastic MC3T3-E1 cells. Osteoblastic cells were cultured for $72 \mathrm{~h}$ in a medium containing $10 \%$ FBS Cells with subconfluency were changed to a medium without FBS in the presence or absence of PTH $\left(10^{-7} \mathrm{M}\right)$ or IGF-I $\left(10^{-8} \mathrm{M}\right)$ with or without staurosporine $\left(10^{-8} \mathrm{M}\right)$ or PD98059 $\left(10^{-7} \mathrm{M}\right)$. After the medium change, the cells were cultured for 24 or $48 \mathrm{~h}$. Total RNAs $(2 \mu \mathrm{g})$ extracted from the cells were analyzed using RT-PCR with specific primers. The figure shows one of four experiments with separate samples. The densitometric data for each mRNA level in the cells cultured for 24 or $48 \mathrm{~h}$ in the presence of PTH (A) or IGF-I (B) with or without each inhibitor were indicated as a percentage of control (mean \pm SEM for four experiments).

\section{Results}

Osteoblastic MC3T3-E1 cells with subconfluency were cultured for 24 or $48 \mathrm{~h}$ in a medium containing either vehicle or various factors without FBS, and the change in regucalcin mRNA expression was examined. Culture with PTH $\left(10^{-7} \mathrm{M}\right)$ for $48 \mathrm{~h}$ caused a significant increase in regucalcin mRNA expression as compared with that of the control value (none) (Fig. 1A). Regucalcin mRNA expression was significantly increased after culture with IGF-I $\left(10^{-8} \mathrm{M}\right)$ for 24 or $48 \mathrm{~h}$ (Fig. 1B).

The effect of $17 ß$-estradiol or $1,25(\mathrm{OH})_{2} \mathrm{D}_{3}$ on regucalcin mRNA expression in osteoblastic cells is shown in Fig. 2. Regucalcin mRNA expression was significantly increased after culture with 173 -estradiol $\left(10^{-10}\right.$ or $\left.10^{-9} \mathrm{M}\right)$ for 24 or $48 \mathrm{~h}$ (Fig. 2A). Culture with $1,25(\mathrm{OH})_{2} \mathrm{D}_{3}\left(10^{-7} \mathrm{M}\right)$ caused a significant decrease in regucalcin mRNA expression in osteoblastic cells (Fig. 2B).

The effect of TNF- $\alpha$ on regucalcin mRNA expression in osteoblastic cells is shown in Fig. 3. Regucalcin mRNA expression was significantly decreased after culture with TNF- $\alpha$ ( 1 or $10 \mathrm{ng} / \mathrm{ml}$ of medium) for 24 or $48 \mathrm{~h}$.

The effect of PTH or IGF-I in increasing regucalcin mRNA expression in osteoblastic cells was examined in the presence of intracellular signaling inhibitors (Fig. 4). Cells were cultured for $48 \mathrm{~h}$ in the presence of PTH $\left(10^{-7} \mathrm{M}\right)$ or IGF-I $\left(10^{-8} \mathrm{M}\right)$ with or without staurosporine $\left(10^{-8} \mathrm{M}\right)$, an inhibitor of protein kinase C, or PD98059 (10 $\left.0^{-7} \mathrm{M}\right)$ an inhibitor of mitosis- 
activated protein (MAP) kinase. The effect of PTH or IGF-I in increasing regucalcin mRNA expression was not seen in the presence of staurosporine or PD98059, respectively.

\section{Discussion}

Bone loss has been induced in the femoral tissues of regucalcin transgenic rats (30). Regucalcin has been expressed in rat bone marrow cells, and osteoclastic bone resorption has been stimulated in regucalcin transgenic rats with increasing age (35). Osteoblastic cell formation from bone marrow cells has been enhanced in regucalcin transgenic rats (36). Exogenous regucalcin has been shown to have stimulatory effects on osteoclastogenesis in bone marrow cell cultures (32) and suppressive effects on osteoblastic differentiation and mineralization in vitro (33). Regucalcin may play an important role in the regulation of bone metabolism.

We examined whether the expression of regucalcin mRNA in osteoblastic cells is hormonally regulated. PTH, $1,25(\mathrm{OH})_{2} \mathrm{D}_{3}$, or TNF- $\alpha$ has stimulated osteoclastic bone resorption (37). PTH, IGF-I, or 17ß-estradiol has had an anabolic effect on osteoblastic cell function $(38,39)$. The receptors of these hormones and cytokines are expressed in osteoblastic MC3T3-E1 cells. Culture with PTH, IGF-I, or 17ß-estradiol enhanced the expression of regucalcin mRNA in osteoblastic cells. Meanwhile, regucalcin mRNA expression was suppressed after culture with $1,25(\mathrm{OH})_{2} \mathrm{D}_{3}$ or TNF- $\alpha$. TNF- $\alpha$ had a potent suppressive effect on regucalcin mRNA expression, suggesting that the cytokine has a role as the negative regulator in regucalcin mRNA expression.

The effect of PTH or IGF- $\alpha$ in increasing regucalcin mRNA expression in osteoblastic cells was completely prevented after culture with staurosporine, an inhibitor of protein kinase C, or PD98059, an inhibitor of MAP kinase. The expression of regucalcin mRNA in osteoblastic cells may be enhanced through intracellular signaling factors.

$17 ß$-estradiol had stimulatory effects on regucalcin mRNA expression in osteoblastic cells, suggesting that the gene expression is mediated through the steroid receptors in the cells.

The effect of TNF- $\alpha$ is mediated through TNF receptorassociated factor (TRAF6) in osteoblastic cells (37). TNF- $\alpha$ was found to suppress regucalcin mRNA expression in osteoblastic cells. The suppressive effect of TNF- $\alpha$ on regucalcin mRNA expression in osteoblastic cells may be mediated through the TRAF6 signaling process.

Regucalcin mRNA expression in osteoblastic cells was significantly decreased after a longer culture with $1,25(\mathrm{OH})_{2} \mathrm{D}_{3}$, suggesting that its expression is suppressed through the steroid receptors.

The endogenous regucalcin in osteoblastic cells has suppressive effects on cell function that is involved in differentiation and mineralization (33). If regucalcin mRNA expression is regulated by various hormones and cytokines which are involved in the regulation of osteoblastic cell function, the endogenous regucalcin may be partly related, in light of hormone and cytokine effects on osteoblastic cells. The present findings support the view that regucalcin may play an important role in the regulation of osteoblastic cell function.
In conclusion, it has been demonstrated that regucalcin mRNA expression is enhanced after culture with PTH, IGF-I, or 17ß-estradiol in osteoblastic MC3T3-E1 cells, and that it is suppressed with $1,25(\mathrm{OH})_{2} \mathrm{D}_{3}$ or TNF- $\alpha$. The expression of regucalcin mRNA was found to be regulated hormonally in osteoblastic cells.

\section{References}

1. Yamaguchi M and Yamamoto T: Purification of calcium binding substance from substance from soluble fraction of normal rat liver. Chem Pharm Bull 26: 1915-1918, 1978.

2. Yamaguchi $M$ and Sugii K: Properties of calcium-binding protein isolated from the soluble fraction of normal rat liver. Chem Pharm Bull 29: 567-570, 1981.

3. Yamaguchi M: Physicochemical properties of calcium-binding protein isolated from rat liver cytosol: $\mathrm{Ca}^{2+}$-induced conformational changes. Chem Pharm Bull 36: 286-290, 1989.

4. Yamaguchi M and Mori S: Effects of $\mathrm{Ca}^{2+}$ and $\mathrm{Zn}^{2+}$ on 5'-nucleotide activity in rat liver plasma membranes: Hepatic calciumbinding protein (regucalcin) reverses the $\mathrm{Ca}^{2+}$ effect. Chem Pharm Bull 36: 321-325, 1988.

5. Shimokawa $\mathrm{N}$ and Yamaguchi $\mathrm{M}$ : Molecular cloning and sequencing of the cDNA coding for a calcium-binding protein regucalcin from rat liver. FEBS Lett 327: 251-255, 1993.

6. Yamaguchi M: A novel $\mathrm{Ca}^{2+}$-binding protein regucalcin and calcium inhibition. Regulatory role in liver cell function. In: Calcium Inhibition. Kohama K (ed). Japan Sci Soc Press, Tokyo and CRC Press, Boca Raton, pp19-41, 1992.

7. Yamaguchi M: Role of regucalcin in calcium signaling. Life Sci 66: 1769-1780, 2000.

8. Yamaguchi M: Role of regucalcin in nuclear regulation of regenerating liver. Biochem Biophys Res Commun 276: 1-6, 2000.

9. Yamaguchi $\mathrm{M}$ : Role of regucalcin in maintaining cell homeostasis and function. Int J Mol Med 15: 372-389, 2005.

10. Misawa $\mathrm{H}$ and Yamaguchi $\mathrm{M}$ : The gene of $\mathrm{Ca}^{2+}$-binding protein regucalcin is highly conserved in vertebrate species. Int J Mol Med 6: 191-196, 2000.

11. Shimokawa N, Matsuda Y and Yamaguchi M: Genomic cloning and chromosomal assignment of rat regucalcin gene. Mol Cell Biochem 151: 157-163, 1995.

12. Thiselton DL, McDowall J, Brandau O, Ramsere J, D'Esposito F, Bhattacharya SS, Ross MT, Hardcastle AJ and Meaindl A: An integrated, functionally annotated gene map of the DXS80269FLK1 interval on human Xp11.3-Xp11.23: Potential hotspot for neurogenetic disorders. Genomics 79: 560-572, 2002.

13. Yamaguchi $\mathrm{M}$ and Isogai $\mathrm{M}$ : Tissue concentration of calciumbinding protein regucalcin in rats by enzyme-linked immunoadsorbent assay. Mol Cell Biochem 122: 65-68, 1993.

14. Shimokawa N and Yamaguchi M: Calcium administration stimulates the expression of calcium-binding protein regucalcin mRNA in rat liver. FEBS Lett 305: 151-154, 1992.

15. Murata $\mathrm{T}$ and Yamaguchi M: $\mathrm{Ca}^{2+}$-administration stimulates the binding of AP-1 factor to the 5'-flanking region of the rat gene for the $\mathrm{Ca}^{2+}$-binding protein regucalcin. Biochem J 329: 157-183, 1998.

16. Murata $\mathrm{T}$ and Yamaguchi M: Promoter characterization of the rat gene for $\mathrm{Ca}^{2+}$-binding protein regucalcin. Transcriptional regulation by signaling factors. J Biol Chem 274: 1277-1285, 1999.

17. Misawa $T$ and Yamaguchi M: Identification of transcriptional factor in the promoter region of rat regucalcin gene: binding of nuclear factor I-A1 to TTGGC motif. J Cell Biochem 84: 795-802, 2002.

18. Sawada N and Yamaguchi M: Overexpression of RGPR-p117 enhances regucalcin gene promoter activity in cloned normal rat kidney proximal tubular epithelial cells: Involvement of TTGGC motif. J Cell Biochem 99: 589-597, 2006.

19. Shimokawa N and Yamaguchi M: Expression of hepatic calcium-binding protein regucalcin mRNA is mediated through $\mathrm{Ca}^{2+} /$ calmodulin in rat liver. FEBS Lett 316: 79-84, 1993.

20. Yamaguchi M and Nakajima M: Involvement of intracellular signaling factors in the serum-enhanced $\mathrm{Ca}^{2+}$-binding protein regucalcin mRNA expression in the cloned rat hepatoma cells (H4-II-E). J Cell Biochem 74: 81-89, 1999.

21. Tsurusaki Y and Yamaguchi M: Suppressive role of endogenous regucalcin in the enhancement of deoxyribonucleic acid synthesis activity in the nucleus of regenerating rat liver. J Cell Biochem 85: 516-522, 2002. 
22. Tsurusaki Y and Yamaguchi M: Role of endogenous regucalcin in the nuclear regulation of regenerating rat liver: Suppression of the enhanced ribonucleic acid synthesis activity. J Cell Biochem 87: 450-457, 2002.

23. Tsurusaki Y, Misawa H and Yamaguchi Y: Translocation of regucalcin to rat liver nucleus: Involvement of nuclear protein kinase and phosphatase regulation. Int J Mol Med 6: 655-660, 2000.

24. Tsurusaki Y and Yamaguchi M: Overexpression of regucalcin modulates tumor-related gene expression in cloned rat hepatoma H4-II-E cells. J Cell Biochem 90: 619-626, 2003.

25. Misawa H, Inagaki $\mathrm{S}$ and Yamaguchi M: Suppression of cell proliferation and deoxyribonucleic acid synthesis in cloned rat hepatoma H4-II-E cells overexpressing regucalcin. J Cell Biochem 84: 143-149, 2002.

26. Nakagawa T, Sawada N and Yamaguchi M: Overexpression of regucalcin suppresses cell proliferation of cloned normal rat kidney proximal tubular epithelial NRK52E cells. Int J Mol Med 16: 637-643, 2005.

27. Izumi T and Yamaguchi M: Overexpression of regucalcin suppresses cell death in cloned rat hepatoma H4-II-E cells induced by tumor necrosis factor- $\alpha$ or thapsigargin. J Cell Biochem 92: 296-306, 2004.

28. Nakagawa $\mathrm{T}$ and Yamaguchi $\mathrm{M}$ : Overexpression of regucalcin suppresses apoptotic cell death in cloned normal rat kidney proximal tubular epithelial NRK52E cells: Change in apoptosisrelated gene expression. J Cell Biochem 96: 1274-1285, 2005.

29. Yamaguchi M, Morooka Y, Misawa H, Tsurusaki Y and Nakajima R: Role of endogenous regucalcin in transgenic rats: suppression of kidney cortex cytosolic protein phosphatase activity and enhancement of heart muscle microsomal $\mathrm{Ca}^{2+}$ ATPase activity. J Cell Biochem 86: 520-529, 2002.
30. Yamaguchi M, Misawa H, Uchiyama S, Morooka Y and Tsurusaki $Y$ : Role of endogenous regucalcin in bone metabolism: Bone loss is induced in regucalcin transgenic rats. Int J Mol Med 10: 377-383, 2002.

31. Yamaguchi M, Igarashi A, Uchiyama S and Sawada N: Hyperlipidemia is induced in regucalcin transgenic rats with increasing age. Int J Mol Med 14: 647-651, 2004.

32. Yamaguchi $\mathrm{M}$ and Uchiyama $\mathrm{S}$ : Regucalcin stimulates osteoclast-like cell formation in mouse marrow cultures. J Cell Biochem 94: 794-803, 2005.

33. Yamaguchi M, Kobayashi $M$ and Uchiyama S: Suppressive effect of regucalcin on cell differentiation and mineralization in osteoblastic MC3T3-E1 cells. J Cell Biochem 96: 543-554, 2005.

34. Chomczyshi P and Sacchi N: Single-step method of RNA isolation by acid guanidium thiocyanate-phenol-chloroform extraction. Anal Biochem 162: 156-159, 1989.

35. Yamaguchi M, Sawada N, Uchiyama S, Misawa H and Ma ZJ: Expression of regucalcin in rat bone marrow cells: Involvement of osteoclastic bone resorption in regucalcin transgenic rats. Int J Mol Med 13: 437-443, 2004.

36. Uchiyama $\mathrm{S}$ and Yamaguchi $\mathrm{M}$ : Bone loss in regucalcin transgenic rats: Enhancement of osteoclastic cell formation from bone marrow of rats with increasing age. Int J Mol Med 14: 451-455, 2004.

37. Asagiri $\mathrm{M}$ and Takayanagi $\mathrm{H}$ : The molecular understanding of osteoclast differentiation. Bone 40: 251-264, 2007.

38. Jilka RL: Molecular and cellular mechanisms of the anabolic effect of intermittent PTH. Bone 40: 1434-1446, 2007.

39. Jotter KV and Perry MJ: High-dose estrogen-induced osteogenesis is decreased in aged $R U N X 2^{+/-}$mice. Bone 41: 25-32, 2007 . 